\title{
Porphyromonas levii
}

National Cancer Institute

\section{Source}

National Cancer Institute. Porphyromonas levii. NCI Thesaurus. Code C86658.

A species of obligately anaerobic, Gram-negative, rod shaped bacteria assigned to the phylum Bacteroidetes. This species is nonmotile, non-spore forming, indole, catalase, lipase, and lecithinase negative, pigmented, produces acid from glucose and lactose, but not sucrose, esculin, cellobiose or ribose, digests gelatin, casein, milk and meat, but does not reduce nitrate or hydrolyze starch, esculin or hippurate. P. levii has been isolated from the bovine rumen and summer mastitis, as well as cattle horn abscess, and is pathogenic to humans. 